\title{
Determination of Traffic Induced Noise Pollution and its Impact on City Dwellers in the Chittagong City Area
}

\author{
Mohammad Nasir Uddin \\ Curator, Department of Anatomy, \\ Armed Forces Medical College, Dhaka, Bangladesh \\ Md. Shahidul Hoque \\ Muhammad Alamgir Islam \\ Assistant Professor, Department of Statistics, \\ University of Chittagong, Chittagong, Bangladesh
}

Doi: 10.19044/esj.2018.v14n8p185 URL:http://dx.doi.org/10.19044/esj.2018.v14n8p185

\begin{abstract}
Chittagong, the port city of Bangladesh, is one of the nosiest cities of the country. Extreme noise is very inimical for human health and environment. Noise pollution implies a discomfort and restlessness caused to humans by unwanted high intensity sound. Motorized traffic is one of the major sources of producing noise in Chittagong city. The present paper deals with determining the level of the noise pollution in Chittagong city area and its impact on city dwellers. In this study noise levels have been measured with digital sound level meter at eight different places of Chittagong city from 6:00 am to 9:00 pm during working days. Time weighted average noise level has been measured at the road side. The data have been analyzed to compute the average, maximum and minimum noise level in decibel $(\mathrm{dB})$ with respect to traffic volume. From the study it was observed that the highest noise level in the road side in Chittagong city was $112 \mathrm{~dB}$ found at New Market and 2 No gate traffic area, which for exceeded the acceptable limit of $60 \mathrm{~dB}$ set by the Government of Bangladesh and minimum sound level $67 \mathrm{~dB}$ was recorded at GEC traffic area. The highest average value is $109.66 \mathrm{~dB}$ found at 2 No gate traffic area and lowest average value is $68.7 \mathrm{~dB}$ found at GEC traffic area. Questionnaire survey was done during the study to determine the health impact on the city dwellers. Most of the common problems, the dwellers suffering from noise pollution are headache, bed temper, sleeplessness, aggravation, hearing problems etc.
\end{abstract}

Keywords: Noise pollution, Human health, Environmental problem, Dwellers 


\section{Introduction}

Noise pollution affects both health and behavior. Unwanted sound (noise) can damage psychological health. Noise pollution can cause hypertension, high stress levels, tinnitus, hearing loss, sleep disturbances, and other harmful effects. Automobile revolution in urban areas has proved to be a big source of noise pollution. Increasing traffic has given rise to traffic jams in congested areas where the repeated hooting of horns by impatient drivers pierces the ears of all road users. Heavy trucks, buses, trains, motor-cycles, scooters and jeeps the list of vehicles is endless but the outcome is same noise pollution.

Noise is derived from the latin world "nausea, implying unwanted sound, or "sound that is loud unpleasant or unexpected (sing et al; 2004). The main Effects of Noise Pollution is hearing Problems. Any unwanted sound that our ears have not been built to filter can cause problems within the body. Constant exposure to loud levels of noise can easily result in the damage of our ear drums and loss of hearing. Beyond these effects, elevated noise levels can create stress, increase workplace accident rates, and stimulate aggression and other anti-social behaviors (Kryter, Karl D.1994) 11. The most significant causes are vehicle and aircraft noise, prolonged exposure to loud music, and industrial noise. In Norway, road traffic has been demonstrated to cause almost $80 \%$ of the noise annoyances reported (Natural Resources and the Environment 2006. pp. 188-189) [2]. Noise health effects are the health consequences of regular exposure, to consistent elevated sound levels. Elevated workplace or environmental noise can cause hearing impairment, hypertension, ischemic heart disease, annoyance, and sleep disturbance. Noise in large cities is considered by the world Health organization to be the third most hazardous type of pollution, right after air and water pollution (Tania and odagiu, 2007) ${ }^{[3]}$.

Noise is obligatory part of our daily lives and has increasingly become a major trouble on the worth of lives. Noise pollution is defined as from of air pollution that an audible unwanted sound that poses a threat to a person's health an well being (Goines et al. 2007) ${ }^{[4]}$. Industrial growth through imported equipment and the awareness of small locally based industries in the developing countries, have led to the beginning of unrestrained and unknown wastes into the environment in liquid, solid and gaseous forms. Besides such obvious forms of pollution, there are also the insidious forms, such as noise pollution (Moela, 2010 ${ }^{[5]}$. Noise is described in terms of loudness and pitch and noise exposure is measured using a logarithmic decibel (dB) scale (NIDC, $2010)^{[6]}$. Noise pollution is not only a problem in the developed countries (Peterson, 1983) ${ }^{[7]}$ it is also a problem for developing countries like Bangladesh (Uddin et al, 2009) ${ }^{[8]}$ with rising population growth , the urbanization in Bangladesh is also taking place at a quick pace. Noise levels 
in general have increased over the years the noise levels in general have increased over the years the noise levels in the cities have increased at about $1 \mathrm{~dB}$ per year for the last 30 years (Wang et al. 2005) ${ }^{[9]}$.

Chittagong is a metropolitan city in Bangladesh, it is also known as port city. There are around 6.5 million people lived in this city (wikipedia). It is located at the estuary of the Karnophuli river in southestern Bangladesh. It faces the Bay of Bengal to its west. With the rising of population, the number of motor vehicle is increasing in the city gradually. Consequently noise pollution in the city is created by the traffic vehicle. Therefore, the intend of the study is to make out the acute zone in terms of noise level in Chittagong city that will be helpful for the planner and decision maker to take obligatory actions.

\section{Objective of the study}

The main aim of this study is to investigate noise pollution in Chittagong city area and its effects on the city dwellers. Keeping the above views in mind the present work was done setting the following objectives:

- $\quad$ To determine the level of noise pollution certain traffic places of Chittagong City area and analyzing its level of severity.

- To quantify the effects of noise pollution.

- To ascertain the impact of noise pollution on the surrounding neighborhood.

- $\quad$ To recommended appropriate strategies to control the level of noise pollution in the city.

\section{Methodology}

\section{Area of the Study}

Chittagong is the administrative capital of Chittagong Division and the main city of Chittagong District. In current years the urban region of Chittagong has appeared as one of the fastest growing cities in the world. With the development and increase of port facilities and the opening of new trade routes, Chittagong has goals of emerging as a leading provincial and global economic hub. For this study certain traffic place (road areas) of Chittagong City Corporation was selected. There were 8 (eight) sampling points selected road area. Like as Agrabad, Deyan Hat, Tiger pass, New Merket, GEC, 2 No Gate, Muradpur, Bhaddarhat.

\section{Description of the sound level meter, (Instrument used)}

The study was performed by a noise level meter (Lutron S1-4001) . The digital sound level meter provide automatic or manual ranging for measurement ranges from 40 to $130 \mathrm{~dB}$, and features $0.1 \mathrm{~dB}$ resolutions. The meter allows to select between fast and slow response times as well as A and 
$\mathrm{C}$ weighting. A maximum hold function is provided. Jacks on the meter provide AC analog output.

\section{Collection of data}

Noise measurements were performed between 6 am to $9 \mathrm{pm}$ for different road areas when there was no rain or wind. Sound Pressure level was manually recorded at intervals of 30 minute. The data was collected directly by a questionnaire method. I engaged myself in collection information from the respondents. As per scheduled questionnaire was developed for the study. Person to person interview was conducted. Total numbers of hundred respondents (including shopkeepers, house wife, Businessman, Driver, transport Staff, Day Laborer and hawkers) were randomly selected from different points of the study area. The questioner focused on sources, causes effects, and environmental risk factor for health.

Secondary data and information was collected from different governmental and nongovernmental organizations, statistical report, articles, published paper official records, Literature review and internet. However noise pollution problems are new to Bangladesh so data availability is rare for this study.

\section{Analysis of data}

The composed data was analyzed and interpreted for final appearance with the help of statistical techniques with frequency distribution and graphs.

\section{Results and Discussion}

\section{Noise level in different traffic areas of Chittagong city (6 am to 9 pm)}

Agrabad traffic area: In Agrabad area highest and lowest noise level is $109.7 \mathrm{~dB}$ and $69 \mathrm{~dB}$ respectively. In fig- 1 it has been exposed that noise level of this area is always above the accepted level during (6am-9pm). The maximum value was observed at $(9 \mathrm{am}-12 \mathrm{pm})$ and minimum value was observed at (3pm-6pm).

Deyan Hat traffic area: In fig-2 noise level (6am-9pm) of deyan Hat traffic area has been shown. The figure shows that the highest noise level of Deyan Hat traffic area is $107.9 \mathrm{~dB}$ during (9am-12pm) and lowest noise level is $68.5 \mathrm{~dB}$ during $(12 \mathrm{pm}-3 \mathrm{pm})$. Deyan Hat is another mixed zone area where several shopping malls and some industry and garments factory situated. According to Ahmed (1998) the limit of acceptable noise level is $60 \mathrm{~dB}$ in mixed zone areas.

Tiger pass traffic area: In fig- 3 shows variation of intensity of noise Vs time that highest and lowest noise of this traffic area is $106.7 \mathrm{~dB}$ and 69 $\mathrm{dB}$ during (3pm-6pm) respectively. It has been also noticed that noise level of this area is always above from accepted level. 
New Merket taffic area:In fig-4 represent the maximum (highest) noise level of Newmerket traffic area is $112 \mathrm{~dB}$ during (12pm-3pm) and minimum (lowest) noise level $71 \mathrm{~dB}$ during (9am-12pm). New market is mixed zone area. This is the nosiest area of Chittagong city because several shopping malls, hawkers market, super store, intercity bus and lagona station and train station situated. Highest noise level $112 \mathrm{~dB}$ observed of this area.

GEC traffic area: In fig-5 noise level (6am-9pm) of GEC traffic area has been shown. The figure represent that the highest noise level is $105 \mathrm{~dB}$ during (9am-12pm) and lowest noise level is $67 \mathrm{~dB}$ during (3pm-6pm).

2 No Gate traffic area: In fig-6, 2 No gate is mixed zone area where several shopping malls and train station situated. The maximum value $112 \mathrm{~dB}$ was noticed at $(9 \mathrm{am}-12 \mathrm{pm})$ and minimum value $72 \mathrm{~dB}$ was noticed at (6am$9 \mathrm{pm})$. It has been also shown that noise level of this area is always above the accepted level during (9am-12pm).

Muradpur Traffic area: Shows fig-7 noise level from (6am-9pm) of muradpur traffic area of Chittagong city. The maximum noise level $108.9 \mathrm{~dB}$ within ( $9 \mathrm{am}-12 \mathrm{pm}$ ) and minimum noise level $69.5 \mathrm{~dB}$ found at during ( $3 \mathrm{pm}-$ $6 \mathrm{pm})$.

Bhaddar hat traffic area: In fig- 8 noise level (6am-9pm) of Bahhadar hat traffic area has been shown. The figure shows that the highest noise level of Bahddar hat traffic area is $107 \mathrm{~dB}$ and lowest noise level is $68.7 \mathrm{~dB}$. Bahaddar hat is an intercity bus terminal area which is the entrance of Chittagong city. It falls under mixed zone.

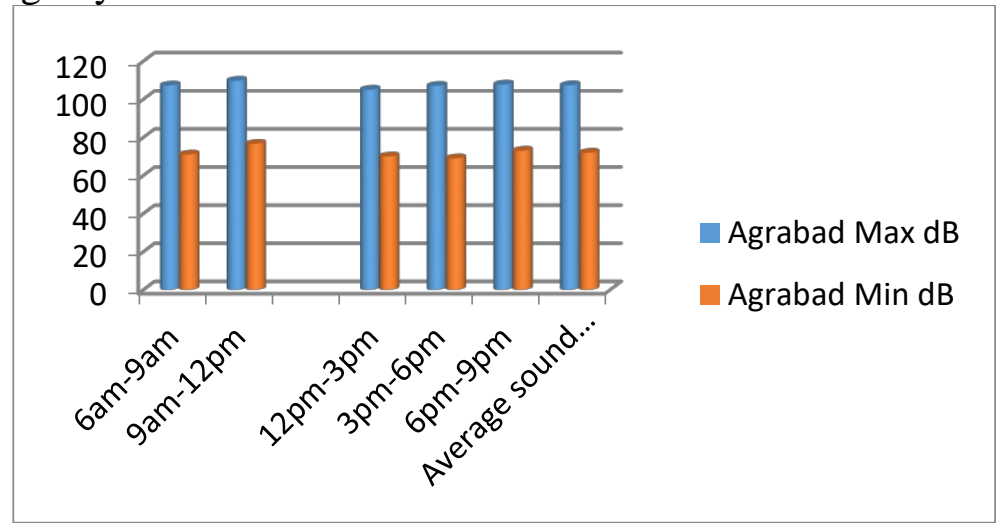

Fig-1: Noise level variation in Agrabad traffic area during (6am-9pm) 


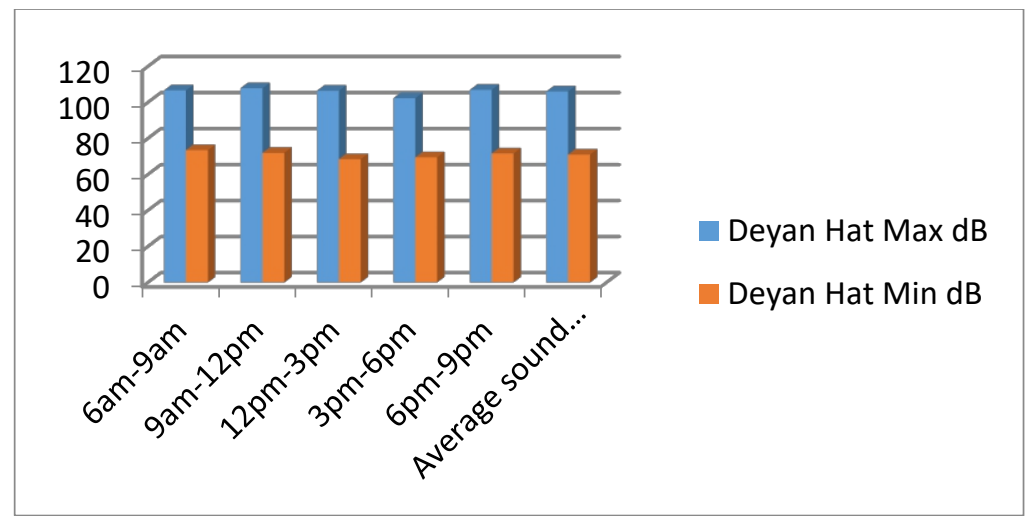

Fig-2: Noise level variation in Deyan Hat traffic area during (6am-9pm)

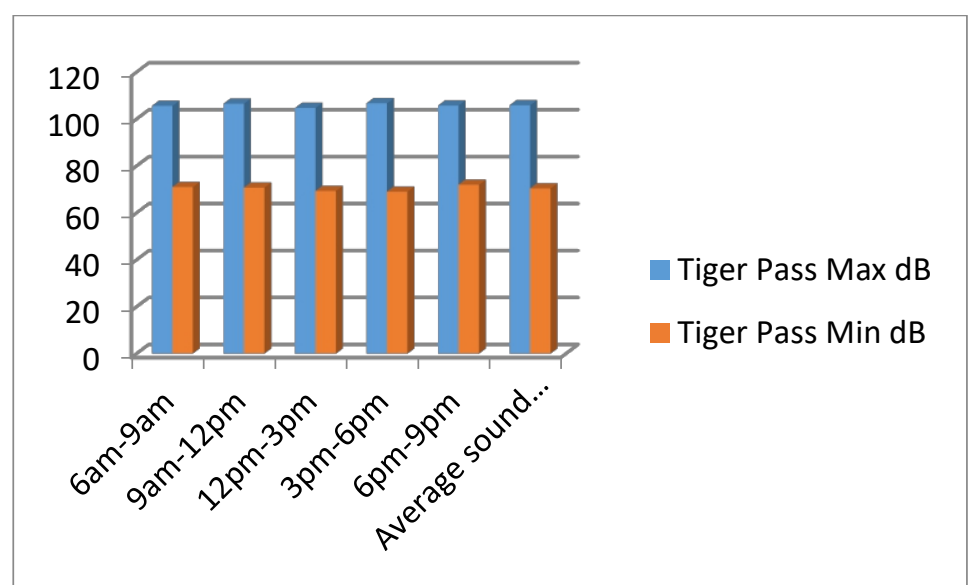

Fig-3: Noise level variations in Tiger pass traffic area during (6am-9pm)

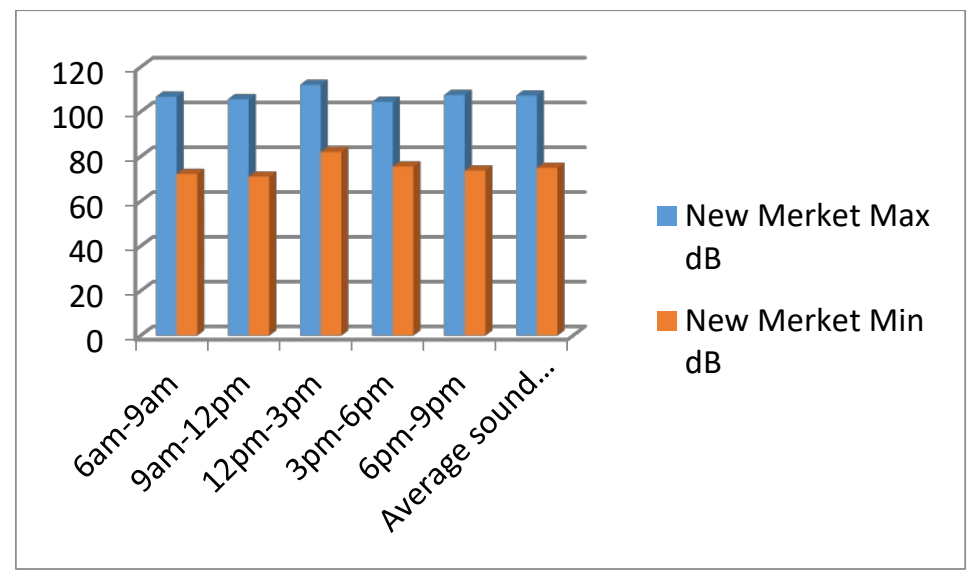

Fig-4: Noise level variation in New Market traffic area during (6am-9pm) 


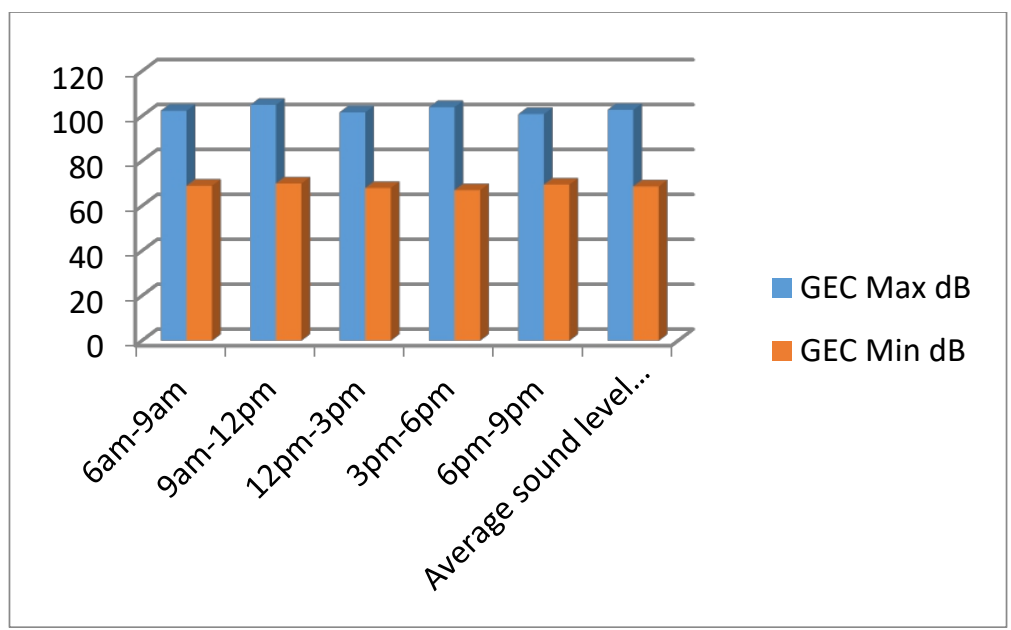

Fig-5: Noise level variation in GEC traffic area during (6am-9pm)

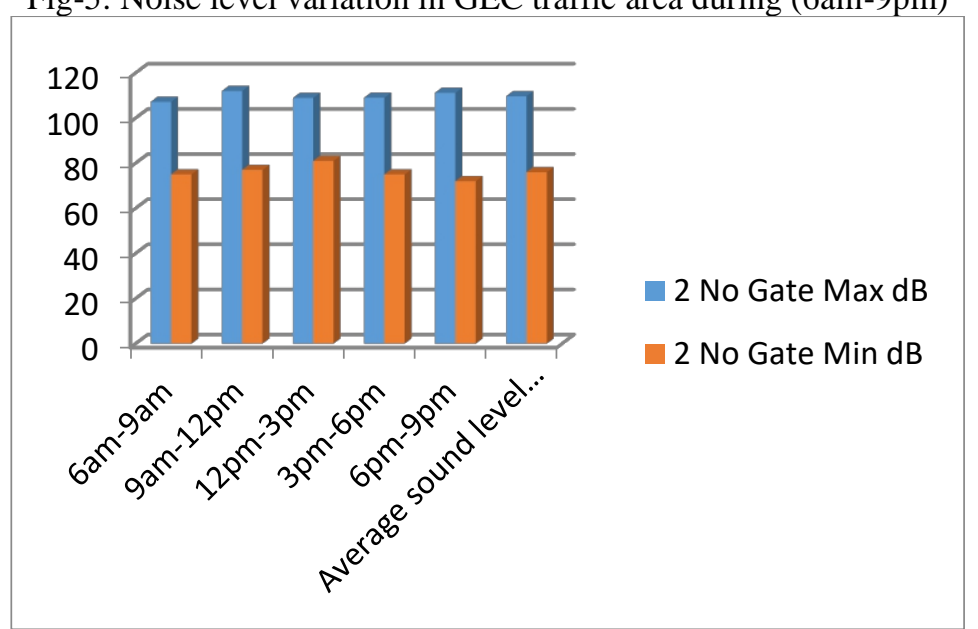

Fig-6: Noise level variation in 2 No Gate traffic area during (6am-9pm)

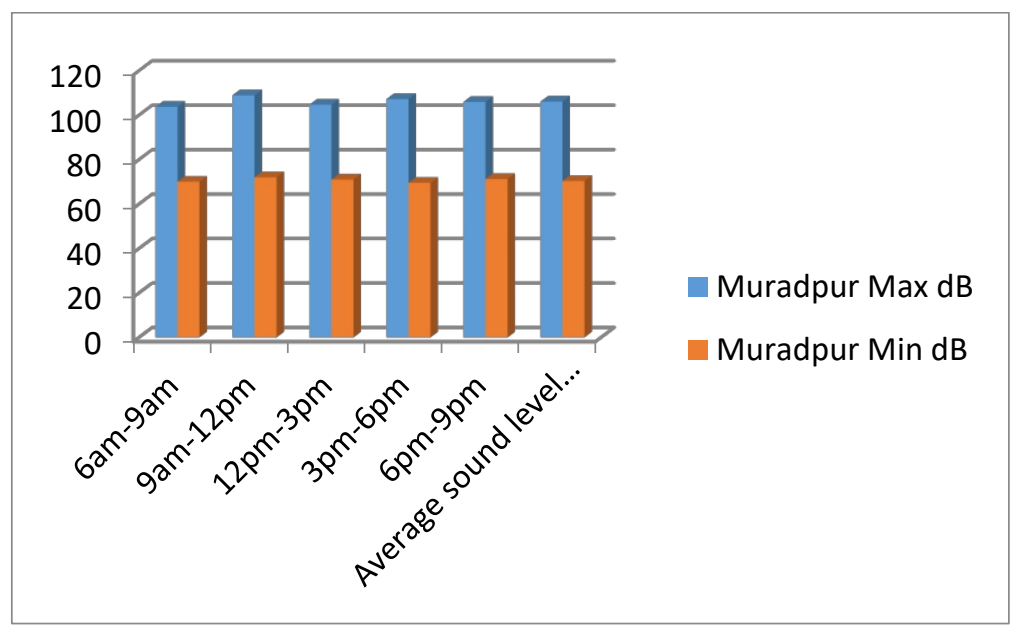

Fig-7: Noise level variation in Muradpur traffic area during (6am-9pm) 


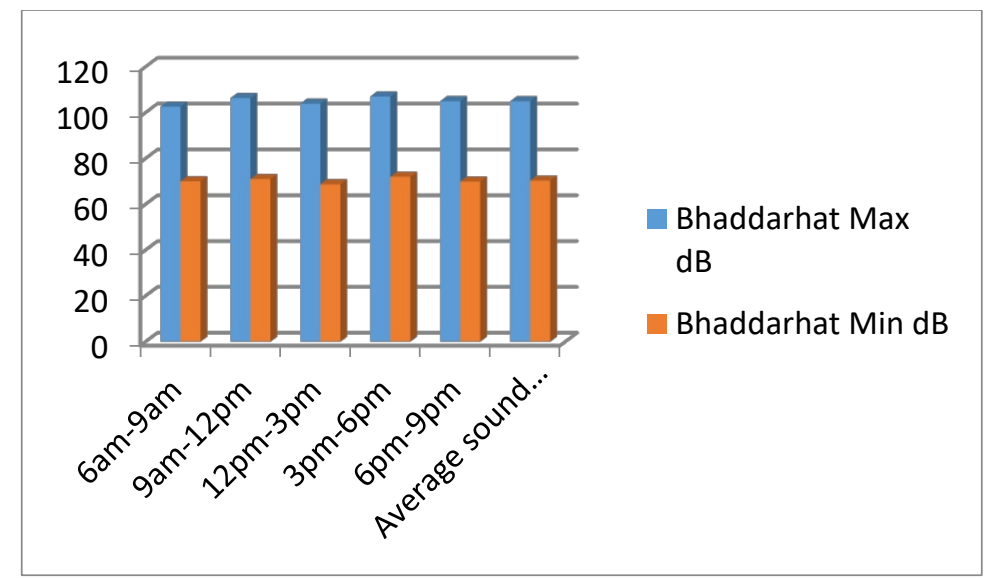

Fig-8: Noise level variation in Bhaddarhat traffic area during (6am-9pm)

Table-1: Noise level variation (6am-9pm) of road areas of Chittagong city.

\begin{tabular}{|c|c|c|c|c|c|c|c|c|c|c|c|c|c|c|c|c|}
\hline \multirow[b]{2}{*}{$\begin{array}{c}\text { Time } \\
\text { Interval }\end{array}$} & \multicolumn{2}{|c|}{ Agrabad } & \multicolumn{2}{|c|}{ Deyan Hat } & \multicolumn{2}{|c|}{ Tiger Pass } & \multicolumn{2}{|c|}{ New Merket } & \multicolumn{2}{|c|}{ GEC } & \multicolumn{2}{|c|}{2 No Gate } & \multicolumn{2}{|c|}{ Muradpur } & \multicolumn{2}{|c|}{ Bhaddarhat } \\
\hline & $\begin{array}{c}\operatorname{Max} \\
\mathrm{dB}\end{array}$ & $\begin{array}{c}\text { Min } \\
\mathrm{dB}\end{array}$ & $\begin{array}{c}\operatorname{Max} \\
\mathrm{dB}\end{array}$ & $\begin{array}{c}\text { Min } \\
\mathrm{dB}\end{array}$ & $\begin{array}{c}\operatorname{Max} \\
\mathrm{dB}\end{array}$ & $\begin{array}{c}\text { Min } \\
\mathrm{dB}\end{array}$ & $\begin{array}{c}\mathrm{Max} \\
\mathrm{dB}\end{array}$ & $\begin{array}{c}\text { Min } \\
\mathrm{dB}\end{array}$ & $\begin{array}{c}\operatorname{Max} \\
\mathrm{dB}\end{array}$ & $\begin{array}{c}\text { Min } \\
\mathrm{dB}\end{array}$ & $\begin{array}{c}\mathrm{Max} \\
\mathrm{dB}\end{array}$ & $\begin{array}{c}\text { Min } \\
\text { dB }\end{array}$ & $\begin{array}{c}\operatorname{Max} \\
\mathrm{dB}\end{array}$ & $\begin{array}{c}\text { Min } \\
\mathrm{dB}\end{array}$ & $\begin{array}{c}\mathrm{Max} \\
\mathrm{dB}\end{array}$ & $\begin{array}{c}\text { Min } \\
\mathrm{dB}\end{array}$ \\
\hline $\begin{array}{l}\text { 6am- } \\
9 \mathrm{am}\end{array}$ & 107.2 & 71 & 106.7 & 73.5 & 105.6 & 71 & 106.7 & 72.2 & 102.4 & 69 & 107.2 & 75 & 103.7 & 70 & 102.6 & 70 \\
\hline $\begin{array}{l}9 \mathrm{am}- \\
2 \mathrm{pm}\end{array}$ & 109.7 & 76.6 & 107.9 & 72 & 106.5 & 70.7 & 105.6 & 71 & 105 & 70 & 112 & 77 & 108.9 & 72 & 106.3 & 71 \\
\hline $\begin{array}{c}12 \mathrm{pm}- \\
\mathrm{pm}\end{array}$ & 105 & 70 & 106.5 & 68.5 & 104.7 & 69.3 & 112 & 82 & 101.7 & 68 & 108.9 & 81 & 104.7 & 71 & 103.9 & 68.7 \\
\hline $\begin{array}{l}3 \mathrm{pm}- \\
6 \mathrm{pm}\end{array}$ & 107 & 69 & 102.4 & 69.5 & 106.7 & 69 & 104.4 & 75.5 & 104 & 67 & 109 & 75 & 107.2 & 69.5 & 107 & 72 \\
\hline $\begin{array}{l}6 \mathrm{pm}- \\
9 \mathrm{pm}\end{array}$ & 107.7 & 73 & 107 & 71.7 & 105.7 & 72 & 107.5 & 73.7 & 100.9 & 69.5 & 111.2 & 72 & 105.9 & 71.2 & 105 & 69.9 \\
\hline $\begin{array}{l}\text { Average } \\
\text { sound } \\
\text { level } \\
(\mathrm{dB})\end{array}$ & 107.32 & 71.94 & 106.1 & 71.04 & 105.84 & 70.4 & 107.24 & 74.88 & 102.8 & 68.7 & 109.6 & 76 & 106.08 & 70.34 & 104.96 & 70.32 \\
\hline
\end{tabular}

\section{Noise level variations of road areas of Chittagong city}

From Table.-1and above figures it has been shown that Maximum noise level from 6am-9pm of 8 (eight) road areas (agrabad, Deyan hat, tigerpass , Newmarket, GEc , 2 No Gate, Muradpur, Bahdorhat) are109.7 dB, $107.9 \mathrm{~dB}, 106.7 \mathrm{~dB}, 112 \mathrm{~dB}, 105 \mathrm{~dB}, 112 \mathrm{~dB}, 108.9 \mathrm{~dB}, 107 \mathrm{~dB}$ respectively and the minimum noise level of these areas are $69 \mathrm{~dB}, 68.5 \mathrm{~dB}, 69 \mathrm{~dB}, 71 \mathrm{~dB}$, $67 \mathrm{~dB} 72 \mathrm{~dB}, 69.5 \mathrm{~dB}, 68.7 \mathrm{~dB}$ respectively.

Highest noise level found at Newmarket and 2 No Gate traffic area $112 \mathrm{~dB}$ during $12 \mathrm{pm}-3 \mathrm{pm}$ (newmarket), 9am-12pm (2 no gate) respectively. Minimum noise level was found at GEC traffic area $67 \mathrm{~dB}$ during $3 \mathrm{pm}-6 \mathrm{pm}$. 


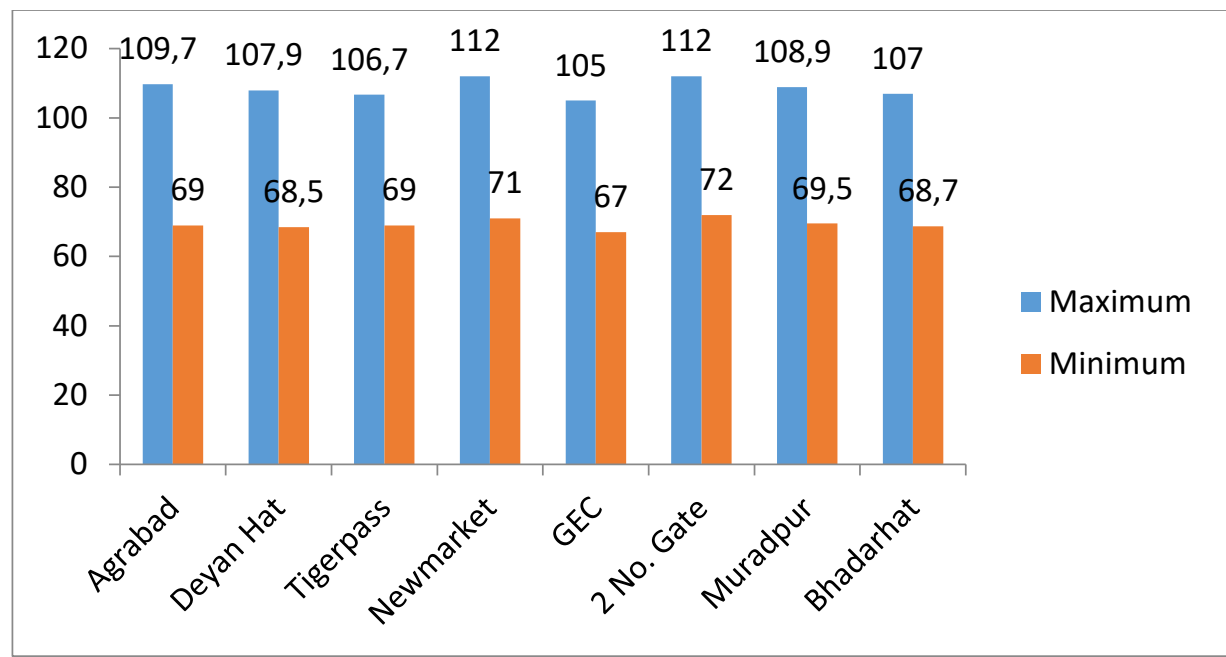

Fig-09: Maximum and Minimum Sound Level (6am-9pm) of different Traffic area in Chittagong city

\section{Average noise level (6am-9pm) of different road areas of Chittagong city corporation}

From Table-1 it has seen that the maximum average noise level of Agrabad, Deyan hat , Tigerpass, New market, GEC, 2 No Gate, Muradpur and Bhaddarhat is $107.32 \mathrm{~dB}, 106.1 \mathrm{~dB}, 105.84 \mathrm{~dB}, 107.24 \mathrm{~dB}, 102.8 \mathrm{~dB}, 109.66$ $\mathrm{dB}, 106.08 \mathrm{~dB}, 104.96 \mathrm{~dB}$ respectively. The minimum average noise level of these areas is $71.94 \mathrm{~dB}, 71.04 \mathrm{~dB}, 70.4 \mathrm{~dB}, 74.88 \mathrm{~dB}, 68.7 \mathrm{~dB}, 76 \mathrm{~dB}, 70.34$ $\mathrm{dB}, 70.32 \mathrm{~dB}$ respectively. Most of the places are above the accepted level. Highest average value is $109.66 \mathrm{~dB}$ found at 2 no gate traffic areas and lowest average value is $68.7 \mathrm{~dB}$ found at GEC traffic areas.

Most of the places highest average noise level is around $105 \mathrm{~dB}$ and lowest average noise level is around $70 \mathrm{~dB}$ which is exceed acceptable limit.

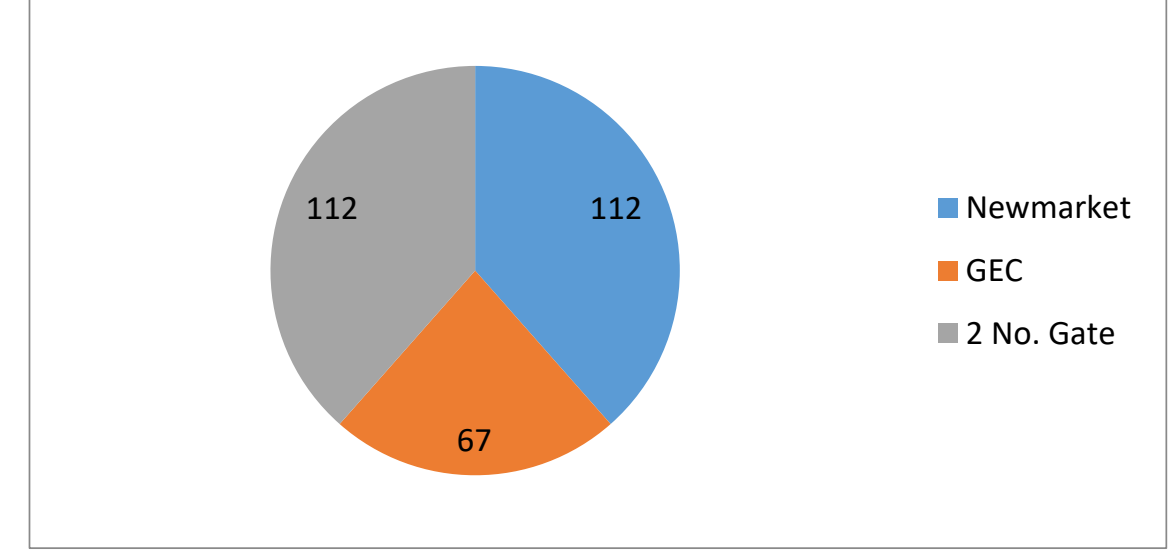

Fig-10: Highest (Maximum) and Lowest (Minimum) Sound Level of Traffic area in Chittagong city 


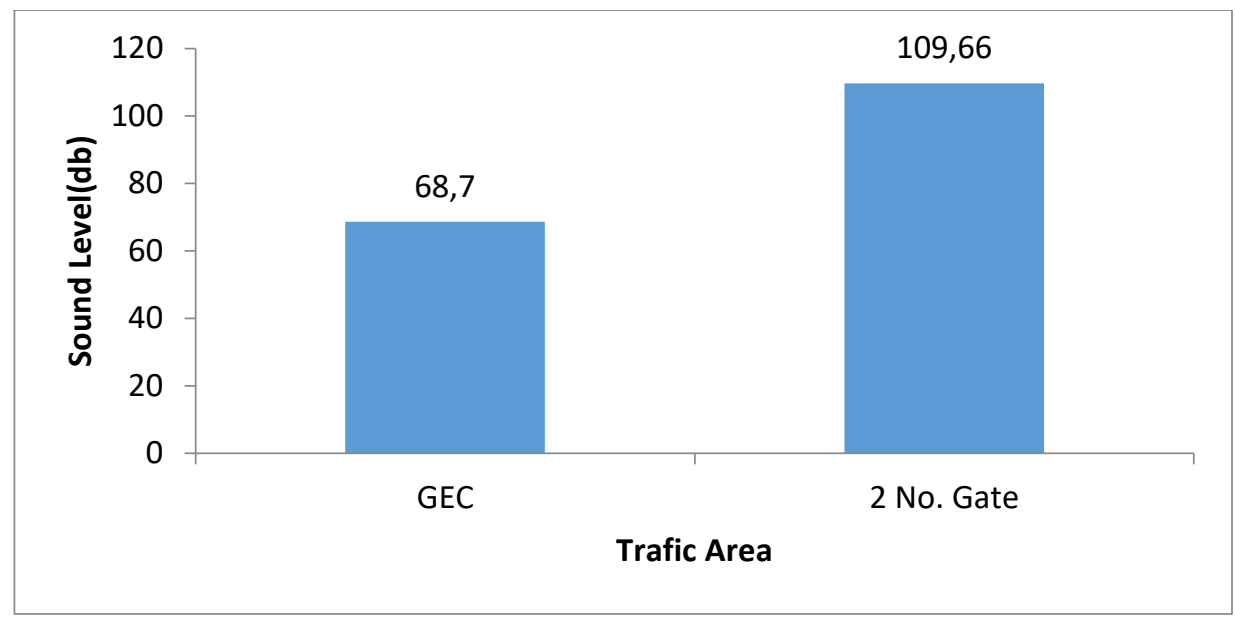

Fig-11: Highest (Maximum) and Lowest (Minimum) Average Sound Level of Traffic area in Chittagong city.

\section{Standard sound level of Bangladesh:}

Standard sound level on different specific areas / locations in Bangladesh such as Residential Area, Commercial Area, Industrial Area, Silent Area, Traffic Area etc are shown (Table -2).

The areas within 100 meters of hospitals or educational institutions or any government designed institutions or establishment are to be considered as silent zones. In these silent (calm) zones horns of vehicles or any other sound or the use of loud speaker is prohibited.

Table-2: Sound level on different specific areas / locations

\begin{tabular}{ccc}
\hline Specific Area & \multicolumn{2}{c}{ Acceptable sound level in dB } \\
& Day time & Night time \\
\hline Residential Area & 50 & 40 \\
Commercial Area & 70 & 60 \\
Industrial Area & 75 & 70 \\
Silent Area & 45 & 35 \\
Traffic Area & $70-75$ & Not yet standardized \\
\hline
\end{tabular}

Source: Anon. 2003; DoE, Chittagong Division, 2003

Note: Day time is recognized as from 06.00 am to $09.00 \mathrm{pm}$ and Night time is recognized as from $09.00 \mathrm{pm}$ to $06.00 \mathrm{am}$

Table -3: Noise level standard according to WHO:

\begin{tabular}{cccc}
\hline S/N & Category of Area & \multicolumn{2}{c}{ Sound level dB (A) } \\
& & Day time & Night time \\
\hline 1 & Silence Area & 45 & 35 \\
2 & Residential area & 50 & 40 \\
3 & Mixed area (Mainly residential area, and & 60 & 50 \\
& also simultaneously used for commercial & & \\
\multicolumn{4}{c}{ and Industrial purpose) } \\
4 & Commercial Area & 70 & 60 \\
5 & Industrial Area & 75 & 70 \\
\hline
\end{tabular}

Source: (DoE, 1997; WHO, 2002) 


\section{Impact of noise pollution on the people of Chittagong city dwellers}

For measuring the impact of noise pollution on the people of Chittagong city dwellers we have been collected 100 members of the general public surveyed during the study. Among them $65 \%$ were male and $35 \%$ were female.

To classify the main three sources of noise pollution, the respondents were pointed out motor vehicle ( $85 \%)$, followed by miking $(35 \%)$ industrial activities (30\%), construction (20\%) and other $10 \%$ are shown figure-12

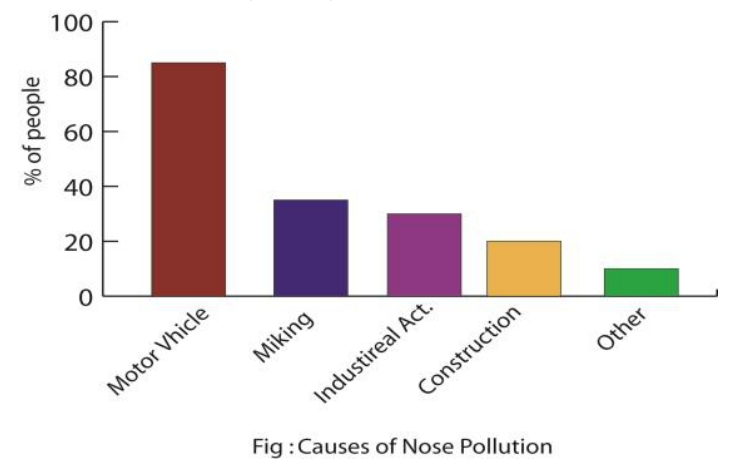

Fig -12: Causes of Noise Pollution

To abate of noise pollution problems $60 \%$ respondents recommended for rising of awareness, $10 \%$ recommended for banning of hydraulic horn and $25 \%$ recommended have to be enforcement environment law and $5 \%$ did not any Comments are shown in figure- 1 .

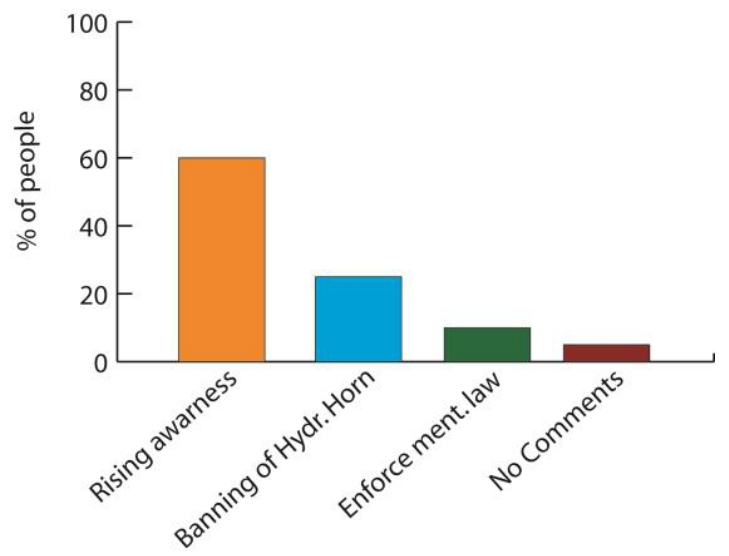

Fig : Ways to reduce Noise Pollution

Fig - 13: Ways to reduce Noise Pollution

On an average $85 \%$ respondents said that noise pollution as unbearable incident, $7 \%$ react as bearable and $8 \%$ react as no problem are shown in figure14. Therefore we may conclude that most of the respondents react that noise pollution is a problem. 


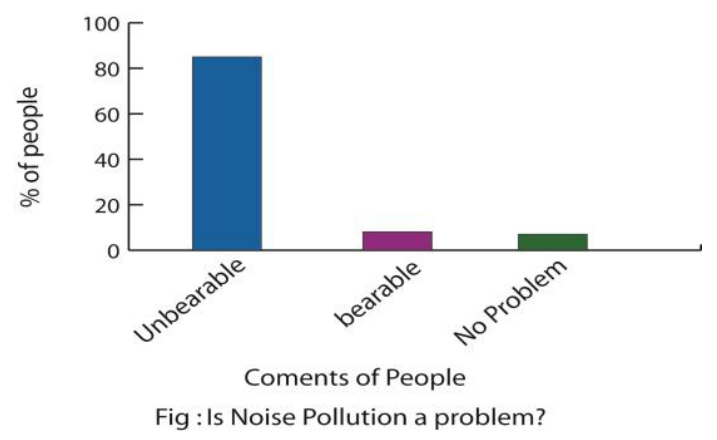

Fig - 14: Is Noise Pollution a Problem

From the following figure-15, it has seen that $80 \%$ dwellers suffering from headache, $25 \%$ from bad temper, $35 \%$ from hearing problem and $40 \%$ from sleeplessness.

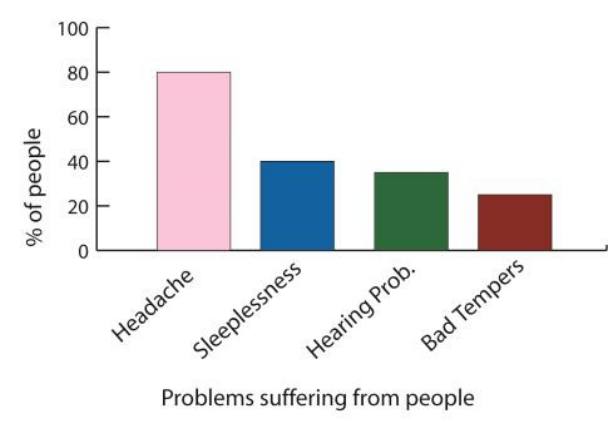

Fig : Problems suffering from Noise Pollution

Fig -15: Problem suffering from Noise Pollution.

\section{Conclusion}

The study concerning average maximum and minimum noise level with respect to acceptable limit demonstrated that most of the places were at alarming noise level. Highest noise level was found at New Market and 2 No gate traffic area $112 \mathrm{~dB}$ and lowest noise level was found at GEC $67 \mathrm{~dB}$. The highest average value is $109.66 \mathrm{~dB}$ found at 2 No gate traffic area and lowest average value is $68.7 \mathrm{~dB}$ found at GEC traffic area. It is remarkably noticed that almost all traffic area highest noise level has been measured $109.7 \mathrm{~dB}$ (agrabad), $107.9 \mathrm{~dB}$ (Deyan Hat), $105 \mathrm{~dB}$ (GEC), $112 \mathrm{~dB}$ (2 No Gate), 108dB (Muradpur) respectively during (9am-12pm). Because this is peak time for office going passenger and all educational institutions fully open this time. In this reason different type of motor vehicle are being gathered in different road side and emitted severe noise intensity.

A prescheduled questioner survey was performed. The study observes that most of the people are unaware about noise pollution. But many people are affected by noise pollutions impact. Unawareness of the population about 
noise pollution is also a factor for increasing noise pollution. It is necessary to grow awareness about noise pollution. The results of the study show that the level of noise in Chittagong city Corporation area is far above the accepted level of Department of Environment (DoE) Bangladesh. Even in silent zone like hospitals and school areas, noise levels are much higher than the accepted level. This has serious implication on general health as well as mental health and well being of the citizens of Chittagong city corporation area.

\section{Recommendation}

Noise may be expressed as sound without agreeable quality or as a redundant or undesired sound. With the growing population in the Chittagong city number of vehicles are increasing. But number of roads or size of the roads is not rising. As a result noise level is increasing gradually. The following recommendation may help to reduce the noise pollution:

- $\quad$ Peoples must be made conscious and educated about noise pollution and its effect through adequate news, media, TV, radio etc.

- $\quad$ Traffic regulations should be imposed strictly to control horn sound. Road Signs about maximum noise speed and horn must be place at relevant areas. Public awareness is required. Awareness is also required for transport workers. Overtaking tendency must be stopped. This study will be helpful to raise awareness and strategy about noise pollution.

- The convex lens should be mounted on the traffic square. It is the round mirror which gives the image of person coming from the backside so there is no need of giving horn indicator and we can decrease the noise up to $25 \%$. In industries, the noisy machines must be enclosed in a box like structure having sound absorbing materials on its inner surfaces. There will decrease the noise from propagating and will out off the noise at the source only.

- Imperative measures should be taken to control the noise pollution. Special measures should be taken to construct road and road side faces buildings.

\section{References:}

1. Kryter, Karl D. (1994). The handbook of hearing and the effects of noise: physiology, psychology, and public health. Boston: Academic Press. ISBN 0-12-427455-2.

2. Jump up "10. Noise" (PDF). Natural Resources and the Environment 2006. pp. 188-189. Archived from the original (PDF) on November 14, 2011.

3. Tania M., and Odagiu A. Noise Pollution in Uraban Areas- Case Stuy of Cluj-Napoca Town. Bulletin USAMV-CN, 63/2007.

4. Goines, L. and Haglar, L. 2007. Noise Pollution: A Modern Plague. Southern Medical journal. March; 100(3): 287-293. 
5. Moela R.D. (2010). The impact of traffic noise pollution on the population of strubensavalley in roodepoort.

6. NIDC Fact sheet. 2010. Noise induced Hearing loss. U.S. Department of health and Human services, National Institute of Health, National Institute of Deafness and other communication disorders.

7. Peterson, Y. 1983. Speech the legibility of normal listeners and persons with impaired hearing in traffic noise. Journal of sound vibration. 90:341-360.

8. Uddin, M. J.; Rahman M.A and Roy, R.2009. Noise mapping and their Interpretations of Shabagh area, Dhaka, Bangladesh, J, of Env, Res.,7:43-51

9. Wang, L.k.; Pereira, Norman. C. and Yung T. 2005. "Advanced air and Noise pollution", Human press, Totowa, Newjersey. pp.304-308.

10. NIDC Fact sheet. 2010. Noise induced Hearing loss.U.S. Department of health and Human services, National Institute of Health, National Institute of Deafness and other communication disorders.

11. M.T. Islam, N.Nahar, M.J.Islam, M.A.Islam and M.A.M.Hossen(2015). "Traffic Induced Noise Pollution and its Impact on Human Health in Chittagong City Corporation'. J.Environ. Sci. \& Natural Resources, 8(2): 37-40.

12. Chauhan, A.; Pawar, M.; Kumar, D.; Kumar, N. and Kumar, R. 2010. "Assesment of Noise level status in different Areas of Moradabad city," Reportland opinion; 2(5), 5961p.

13. M.N.Bari, A.Biswas and A.A.Baki(2017). " Determination of Noise Level of Different Places of Rajshahi City'. ICPACE.

14. Ayaz, S.B. and Rahman, M.M. (2011). Assessment of Roadway Noise Level and Potential Mitigation Measures. Vol. 1, Issue 2, pp 47. 